International Journal of Social Science And Human Research

ISSN(print): 2644-0679, ISSN(online): 2644-0695

Volume 03 Issue 11 November 2020

DOI: $10.47191 /$ ijsshr/v3-i11-03

Page No : 254-260

\title{
The Relationship between Prefered Learning Styles, Reading Strategies and Reading Achievement of Efl at Thai Nguyen University, Vietnam
}

\author{
${ }^{1}$ Dang Thi Thanh Huong, ${ }^{2}$ Ph.D Nguyen Thi Bich Diep, B.A \\ ${ }^{1}$ School of Foreign Languages, Thai Nguyen University \\ ${ }^{2}$ Thai Nguyen University of Remoted Education
}

\begin{abstract}
The present study was conducted at the School of Foreign Languages, Thai Nguyen University, Vietnam. There were 132 second years students participated in the study. The study employed quantitative research design. The instruments used in the study included the Perceptual Learning Style Preference Questionnaire (PLSPQ) developed by Reid (1987); the Survey of reading strategies (SORS) which was a 30-item self-assessment instrument developed by Sheorey and Mokhtari (2002), and a simulated IELTS reading test. The findings of the study revealed that there was a statistically significant difference in the uses of reading strategies by different learning styles. The Visual language learners used the most reading strategies $(M=2.92)$. The Auditory language learners ranked the second $(\mathrm{M}=2.50)$. Tactile and Kinesthetic learners used reading strategies at low level $(\mathrm{M}=2.0)$. Group language learners used the least reading strategies $(\mathrm{M}=1.04)$. In terms of reading achievement among different learning styles, the results of the study showed that there was a statistically difference on the reading achievement by learners of different learning styles. The Visual language learners achieved highest scores $(\mathrm{M}=5.49)$. Tactile language learners ranked the second of $\mathrm{M}=4.5$. Auditory and Kinesthetic language learners scored almost similar of $M=3.36$ and $M=3.72$ respectively. Group and Individual learners ranked the last of $\mathrm{M}=2.83$ and $\mathrm{M}=2.77$.
\end{abstract}

Key words: Language Learning Style, Reading Strategies, Reading Achievement.

\section{INTRODUCTION}

\subsection{Rationales}

In terms of language learning, reading is considered as one of the most crucial language skills serving as the foundation for other language skills to be developed, especially for academic achievements at tertiary level. It is thought to be the primary means for gaining access to various sources of information, providing the basis for "synthesis and critical evaluation skills" (Celce-Murcia, 2001, p. 187). Anderson (2003) considers reading as "an essential skill which is most important skill to master for most of the learners of English in order to ensure success in learning" (p. 2).

Being aware of learning styles of the learners will help teachers, instructors, to develop learning tasks that address individual learning needs. If a particular approach to learning is encouraged by a teacher, there is a possibility that some pupils will work and learn less effectively than others in the class. For this reason, an awareness of learning styles is important for teachers. Learning style awareness should make an impact on pedagogy - the ways in which teachers choose to teach - and should help teachers to a better understanding of the needs of learners, as well as to an awareness of the need to differentiate materials, not only by level of difficulty but also by learning style (Prichard, 2009, p.42). Alternatively, students with knowledge of their own preferences are empowered to use various techniques to enhance learning, which in turn may impact overall educational satisfaction. Claxton \& Murrell (1987) stated that knowledge of individual learning style preferences will help students see themselves as learners and the awareness of their learning style preferences can lead to improving performance and learning outcomes.

\subsection{Scope of the study}

The study was carried out with 132 second year students at the School of Foreign Languages, Thai Nguyen University. A one year intensive English course has been delivered to first year students so that they are capable of attending lectures delivered in English. The language achievement to be accepted to enter the majoring phase is B2 (CEFR), i.e. 5.5 in the IELTS or FCE examination. During the English course, students practice four macro language skills focusing on exam preparation. 


\section{The Relationship between Prefered Learning Styles, Reading Strategies and Reading Achievement of Efl at Thai Nguyen University, Vietnam}

\subsection{Aims of the study}

This aim of the study was to examine the relationship between perceptual learning style preferences and students' reading strategies uses. Secondly, the study tried to investigate the relationship that might exists between students' learning styles and reading achievement when students take the IELTS reading module.

\subsection{Research questions}

With the above mentioned aims, the study attempts finding answers to the following research questions;

1.4.1 Is there a statistically significant difference on the uses of reading strategy by different learning styles?

1.4.2 Is there a statistically significant difference on the reading achievement by different learning styles?

\section{LITERATURE REVIEW}

\subsection{Theoretical framework}

The concept of learning styles was introduced in the 1960s. It was based on the principle that all individuals are capable of learning, but varies enormously in the speed and manner in which they pick up new information and ideas, and the confidence with which they process and use them. When teachers recognise that students have different learning styles, they start to become more sensitive to these students' individual differences and needs in the classroom. This could ultimately enhance the teachers' teaching practices (Gappi 2013:70). Unfortunately, when the students' learning styles and the teacher's learning styles do not match, the students are likely to become uncomfortable, bored and inattentive in class, do poorly in tests and ultimately become unmotivated (Felder \& Spurlin 2005:103). Teachers need to help students discover their own learning styles and provide constructive feedback about the advantages and disadvantages of these various styles. Teachers also need to respect students' learning styles and encourage their development whilst at the same time creating opportunities for the students to experiment with other ways of learning (Farajolahi \& Nimvari 2014:159). When students are made aware of their learning styles and strategies, they are not only more prepared for learning, but also more analytic about their learning styles and the strategies they use. Knowledge of one's own learning style is essential in 'learning to learn' as it enables students to take control of their learning whilst still allowing them to maximise their potential for learning (Farajolahi \& Nimvari 2014:159). Therefore, learning styles can be seen to be students' comfort zones or educational conditions under which they learn best (Tuan 2011:287).

\subsection{Reid's Perceptual Learning Style Preferences}

The outstanding model which especially developed for foreign language learners who enrolled at universities to reveal their preferred learning styles is Reid's perceptual learning style preferences. This model was developed in 1987. Reid (1995) mentions that perceptual learning styles identify the differences among learners considering their senses in order to understand, arrange and remain experiences. Reid (1995) claims that three major categories of learning styles are sensory or perceptual learning styles, cognitive learning styles and affective/temperament learning styles. Sensory or perceptual learning style has to do with the physical environment in which we learn, and involves using our senses in order to perceive data. In studies on perceptual learning styles, Dunn (1990) has shown that learners whose preferred learning style is visual may have difficulty learning where the teaching mode is through lectures (auditory) as opposed to auditory learners who may prefer them. Reid purports that research generally refers to learning styles as being points along a continuum. In fact, learners may have more than one learning style and are able to switch or flex styles depending on the environment or task at hand. Cognitive styles relate to thinking, problem solving abilities and the ability to organize information. One type of cognitive learning style research measures field independence and field dependence in learners. The field independent students prefer to learn in a context where rules, instructions, discrete-point tests and imitation are emphasized. The field dependent students, on the other hand, generally prefer cooperative and experiential learning environments. Affective learning/temperament learning style takes students' emotions, values and feelings into consideration. The focus is on the learner (i.e. his or her motivation, level of engagement, interaction and reception to feedback) and how he or she reacts to learning opportunities.

Mulalic, Shad and Ahmad (2009) state that in this classification, the learning styles of learners such as visual, auditory, kinesthetic and tactile are classified according to their perceptions. The other two social aspects, group and individual preferences are listed focusing on how learners learn best. According to Reid (1995) there are six major learning style preferences. These are visual, auditory, kinesthetic, tactile, group and individual major learning style preferences. Individuals can perform well by using these learning style preferences.

\subsubsection{Visual learning styles}

Students who prefer visual learning style as their major style preference learn best by seeing from books, chalkboard and workbooks. They can easily retain and comprehend instructions and information through reading (Reid, 1995).

\subsubsection{Auditory learning styles}

Auditory major learning style preference is another learning style. Mulalic, Shad and Ahmad (2009) reported that auditory learners can learn well through listening information in lectures. Moreover, Reid (1987) mentions that students who prefer 


\section{The Relationship between Prefered Learning Styles, Reading Strategies and Reading Achievement of Efl at Thai Nguyen University, Vietnam}

auditory learning style retain knowledge through reading new material loudly. Audio tapes, lectures and class discussions are beneficial for auditory learners.

\subsubsection{Kinesthetic learning styles}

The other learning style is kinesthetic major learning style preference. Drama, role-play and moving around are the examples of active involvement preferences of kinesthetic learners (Mulalic, Shad \& Ahmad, 2009). Hence, kinesthetic learners learn well by experiencing and involving in classroom practices physically. In this respect, kinesthetic learners need to take part in the activities such as field trips and role playing to keep in mind the information (Reid, 1995).

\subsubsection{Tactile learning styles}

There is one more learning style: Tactile major learning style preference. Reid (1995) indicates that tactile learners can learn well if they the chance to deal with hands-on experiences with materials such as experiments in a laboratory, handling and building models.

\subsubsection{Group learning styles}

In addition, the other learning styles which create the social aspects of the Reid's learning style preferences is group major learning style preference. According to Reid (1995) students who prefer group learning style as their major preference learn easily when they study at least with one of their classmates. Also, when they study with other students they finish their work more successfully.

\subsubsection{Individual learning styles}

The last learning style which has part in the social aspects of Reid's learning style preferences is individual major learning style preference. Learners with individual learning style preference gain knowledge best when they study alone. Furthermore, when they learn on their own they comprehend new material easily (Reid, 1995).

Reid (1995) categorizes learning styles as major, minor and negligible. Each student has major, minor and negligible learning style preferences. Major learning styles point out the area in which the learner could perform well. Minor learning styles show areas in which students still can perform well. On the other hand, negligible learning styles show the areas in which students may have trouble in learning.

\section{3 .RESEARCH METHODOLOGY}

\subsection{Research design}

This study used a descriptive research design. In descriptive research design, data collection is carried out in a structured process. Kumar (2011) argues that the goal of descriptive research is to describe the characteristics of a selected phenomenon and involves the collection of data without manipulation of variables. The study was designed along the lines of a correlation research. Gay (1996) described correlation research as that involving the collection of data in order to determine whether and what degree a relationship exists between two or more quantifiable variables.

\subsection{Participants}

The study used data collected from 132 second year students who are studying at the School of Foreign Languages, Thai Nguyen University (SFL-TNU). The participants have finished an intensive English course which lasted for a year. There were 63 males $(48 \%)$ and 69 females (52\%). Table 1 below indicated the number and percentage of participants by genders.

Table 1: Frequency Table for Nominal Variables

\begin{tabular}{ccc}
\hline Variable & $\mathrm{n}$ & $\%$ \\
\hline Gender & & 47.73 \\
Male & 63 & 52.27 \\
Female & 69 & 0.00 \\
Missing & 0 &
\end{tabular}

Note. Due to rounding errors, percentages may not equal $100 \%$.

\subsection{Data collection instruments}

\subsubsection{Perceptual Learning Style Preference Questionnaire}

The first instrument that was used in the current study was the Perceptual Learning Style Preference Questionnaire (PLSPQ) developed by Reid (1987). It is a self-reporting questionnaire developed on the basis of existing learning style instruments with some changes suggested by non-native speaker. The questionnaire, which was designed and validated for non-native speakers, consists of five statements on each of the six learning style preferences to be measured: visual, auditory, kinaesthetic, tactile, group learning, and individual learning. 
The Relationship between Prefered Learning Styles, Reading Strategies and Reading Achievement of Efl at Thai Nguyen University, Vietnam

\subsubsection{Survey of reading strategies (SORS)}

The second data collection instrument that was used in this study was the Survey of reading strategies (SORS) which was a 30item self-assessment instrument developed by Sheorey and Mokhtari (2002) for measuring "adolescent and adult ESL students' metacognitive awareness and perceived use of reading strategies related to reading academic materials". Its purpose is to evaluate the frequency of reading strategies and the perceived choices that the readers make. SORS items use a 5-point Likert scale that asks the respondents to evaluate according to their reading strategy choice. Students' answers varied based on their opinion at the time of the survey, ranging from 1 to 5 . The format of a Likert item in SORS is 1 ("I never or almost never do this") to 5 ("I always or almost always do this"). The means of SORS can be calculated from 1.0 -2.4 (low use); 2.5-3.4 (medium use); 3.5-5.0 (high use).

\subsubsection{A simulation ELTS reading test.}

The third instrument to collect data for the language reading achievement is a simulation IELTS reading module. The test consists of 40 questions. The points are rounded to 0.5 .

\subsection{Data collection procedures}

First of all, the researcher took permission from the School of Foreign Languages -Thai Nguyen University administration to conduct her study tools on the second year students, and performs the survey on Perceptual Learning Style Preference Questionnaire with the help of the instructors. The instructors helped the researcher conduct the survey during a lecture time. The students were informed to read the survey questionnaires. Participants filled out the background questionnaire in class. Researcher gave volunteers the PLSPQ in the last 15 minutes of the class. In the following week, participants were asked to do the second survey. Participants answered the 30-item SORS. Participants selected metacognitive reading strategies that they thought they used in reading English when filling out SORS. The researcher told the participants that there were no right or wrong answers and asked participants to respond honestly. Researcher collected all the forms.

\section{RESULTS AND DISCUSSIONS}

\subsection{Results of the RQ 1}

Is there a statistically significant difference on the uses of reading strategy by different learning styles?

An analysis of variance (ANOVA) was conducted to determine whether there were significant differences in SORS by learning style. The ANOVA was examined based on an alpha value of 0.05 . The results of the ANOVA were significant, $F(5,126)=$ $271.08, \mathrm{p}<.001$, indicating there were significant differences in SORS among the levels of learning style (Table 3). The eta squared was 0.91 indicating learning style explains approximately $91 \%$ of the variance in SORS. The means and standard deviations are presented in Table 4.

Table 3 Analysis of Variance Table for SORS by Learning_style

\begin{tabular}{cccccc}
\hline Term & $S S$ & $d f$ & $F$ & $p$ & $<.001$ \\
\hline Learning style & 61.53 & 5 & 271.08 & 0.91 \\
Residuals & 5.72 & 126 & & \\
\hline
\end{tabular}

Figure 1 SORS Means by factors levels of Learning style

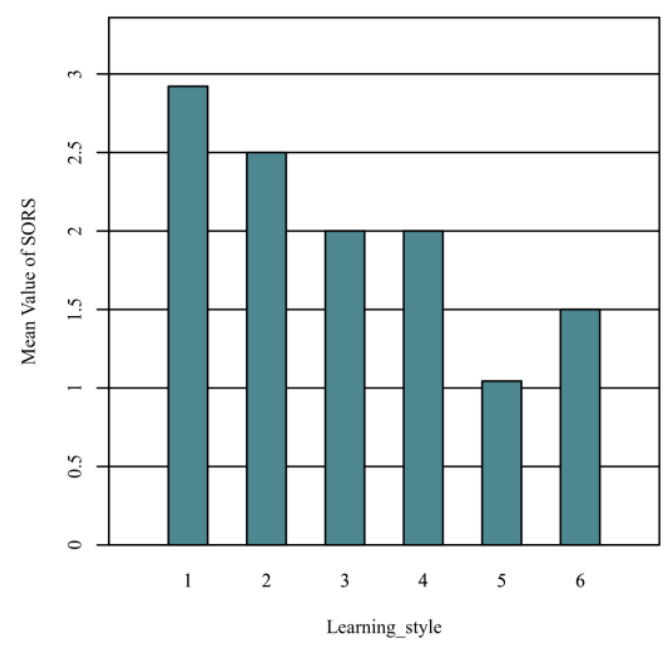


The Relationship between Prefered Learning Styles, Reading Strategies and Reading Achievement of Efl at Thai Nguyen University, Vietnam

Table 4 Mean, Standard Deviation, and Sample Size for SORS by Learning style

\begin{tabular}{cccc}
\hline Combination & $M$ & $S D$ & $n$ \\
\hline Visual & 2.92 & 0.36 & 38 \\
Auditory & 2.50 & 0.00 & 32 \\
Tactile & 2.00 & 0.00 & 15 \\
Kinesthetic & 2.00 & 0.00 & 9 \\
Group & 1.04 & 0.21 & 23 \\
Individual & 1.50 & 0.00 & 15 \\
\hline
\end{tabular}

Note. A '-' indicates the sample size was too small for the statistic to be calculated.

\section{Post-Hoc}

Paired $t$-tests were calculated between each pair of measurements to further examine the differences among the variables. Tukey pairwise comparisons were conducted for all significant effects based on a an alpha of 0.05 . For the main effect of learning style, the mean of SORS for Visual $(M=2.92, S D=0.36)$ was significantly larger than for Auditory $(M=2.50, S D=0.00), p<.001$. For the main effect of learning style, the mean of SORS for Visual $(M=2.92, S D=0.36)$ was significantly larger than for Tactile $(M=2.00, S D=0.00), p<.001$. For the main effect of learning style, the mean of SORS for Visual $(M=2.92, S D=0.36)$ was significantly larger than for Kinesthetic $(M=2.00, S D=0.00), p<.001$. For the main effect of learning style, the mean of SORS for Visual $(M=2.92, S D=0.36)$ was significantly larger than for Group $(M=1.04, S D=0.21), p<.001$. For the main effect of learning style, the mean of SORS for Visual $(M=2.92, S D=0.36)$ was significantly larger than for Individual $(M=1.50, S D=$ $0.00), p<.001$. For the main effect of learning style, the mean of SORS for Auditory $(M=2.50, S D=0.00)$ was significantly larger than for Tactile $(M=2.00, S D=0.00), p<.001$. For the main effect of learning style, the mean of SORS for Auditory $(M=$ $2.50, S D=0.00)$ was significantly larger than for Kinesthetic $(M=2.00, S D=0.00), p<.001$. For the main effect of learning style, the mean of SORS for Auditory $(M=2.50, S D=0.00)$ was significantly larger than for Group $(M=1.04, S D=0.21), p<$ .001 . For the main effect of learning style, the mean of SORS for Auditory $(M=2.50, S D=0.00)$ was significantly larger than for Individual $(M=1.50, S D=0.00), p<.001$. For the main effect of learning style, the mean of SORS for Tactile $(M=2.00, S D=$ $0.00)$ was significantly larger than for Group $(M=1.04, S D=0.21), p<.001$. For the main effect of learning style, the mean of SORS for Tactile $(M=2.00, S D=0.00)$ was significantly larger than for Individual $(M=1.50, S D=0.00), p<.001$. For the main effect of learning style, the mean of SORS for Kinesthetic $(M=2.00, S D=0.00)$ was significantly larger than for Group $(M=$ $1.04, S D=0.21), p<.001$. For the main effect of learning style, the mean of SORS for Kinesthetic $(M=2.00, S D=0.00)$ was significantly larger than for Individual $(M=1.50, S D=0.00), p<.001$. For the main effect of learning style, the mean of SORS for Group $(M=1.04, S D=0.21)$ was significantly smaller than for Individual $(M=1.50, S D=0.00), p<.001$. No other significant effects were found.

\subsection{Results of the RQ 2}

Is there a statistically significant difference on the reading achievement by different learning styles?

An analysis of variance (ANOVA) was conducted to determine whether there were significant differences in level of proficiency by learning style. The ANOVA was examined based on an alpha value of 0.05 . The results of the ANOVA were significant, $F(5$, $126)=89.93, p<.001$, indicating there were significant differences in level of proficiency among the learning style (Table 5). The eta squared was 0.78 indicating learning style explains approximately $78 \%$ of the variance in level of proficiency. The means and standard deviations are presented in Table 6.

Table 5 Analysis of Variance Table for reading achievement by learning style

\begin{tabular}{cccccc}
\hline Term & SS & df & F & p & $\eta_{\mathrm{p}}^{2}$ \\
\hline Learning style & 147.75 & 5 & 89.93 & $<.001$ & \\
Residuals & 41.40 & 126 & & & \\
\hline
\end{tabular}


The Relationship between Prefered Learning Styles, Reading Strategies and Reading Achievement of Efl at Thai Nguyen University, Vietnam

Figure 2 Reading achievement Means by factors levels of learning style

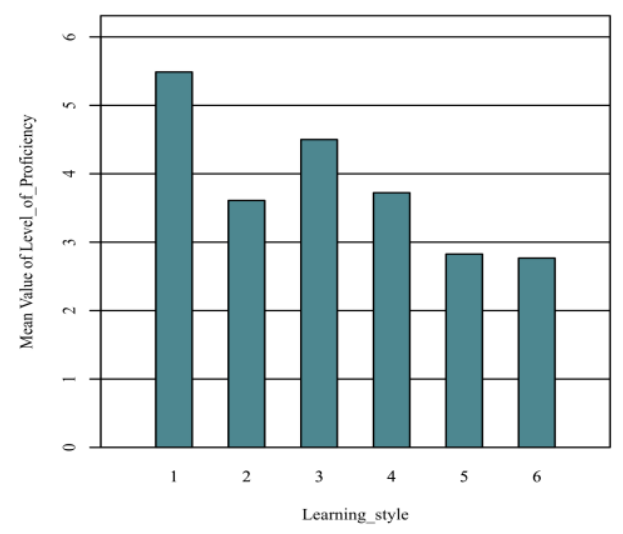

Table 6 Mean, Standard Deviation, and Sample Size for level of proficiency by learning style

\begin{tabular}{|c|c|c|c|}
\hline Combination & $M$ & $S D$ & $n$ \\
\hline Visual & 5.49 & 0.63 & 38 \\
\hline Auditory & 3.61 & 0.86 & 32 \\
\hline Tactile & 4.50 & 0.00 & 15 \\
\hline Kinesthetic & 3.72 & 0.44 & 9 \\
\hline Group & 2.83 & 0.24 & 23 \\
\hline Individual & 2.77 & 0.26 & 15 \\
\hline
\end{tabular}

Note. A '-' indicates the sample size was too small for the statistic to be calculated.

\section{Post-hoc}

Paired $t$-tests were calculated between each pair of measurements to further examine the differences among the variables. Tukey pairwise comparisons were conducted for all significant effects based on a an alpha of 0.05 . For the main effect of learning style, the mean of level of proficiency for Visual $(M=5.49, S D=0.63)$ was significantly larger than for Auditory $(M=3.61, S D=$ $0.86), p<.001$. For the main effect of learning style, the mean of level of proficiency for Visual $(M=5.49, S D=0.63)$ was significantly larger than for Tactile $(M=4.50, S D=0.00), p<.001$. For the main effect of learning style, the mean of level of proficiency for Visual $(M=5.49, S D=0.63)$ was significantly larger than for Kinesthetic $(M=3.72, S D=0.44), p<.001$. For the main effect of learning style, the mean of level of proficiency for Visual $(M=5.49, S D=0.63)$ was significantly larger than for Group $(M=2.83, S D=0.24), p<.001$. For the main effect of learning style, the mean of level of proficiency for Visual $(M=$ $5.49, S D=0.63)$ was significantly larger than for Individual $(M=2.77, S D=0.26), p<.001$. For the main effect of learning style, the mean of level of proficiency for Auditory $(M=3.61, S D=0.86)$ was significantly smaller than for Tactile $(M=4.50, S D=$ $0.00), p<.001$. For the main effect of learning style, the mean of level of proficiency for Auditory $(M=3.61, S D=0.86)$ was significantly larger than for Group $(M=2.83, S D=0.24), p<.001$. For the main effect of learning style, the mean of level of proficiency for Auditory $(M=3.61, S D=0.86)$ was significantly larger than for Individual $(M=2.77, S D=0.26), p<.001$. For the main effect of learning style, the mean of level of proficiency for Tactile $(M=4.50, S D=0.00)$ was significantly larger than for Kinesthetic $(M=3.72, S D=0.44), p=.020$. For the main effect of learning style, the mean of level of proficiency for Tactile $(M=4.50, S D=0.00)$ was significantly larger than for Group $(M=2.83, S D=0.24), p<.001$. For the main effect of learning style, the mean of level of proficiency for Tactile $(M=4.50, S D=0.00)$ was significantly larger than for Individual $(M=2.77, S D$ $=0.26), p<.001$. For the main effect of learning style, the mean of level of proficiency for Kinesthetic $(M=3.72, S D=0.44)$ was significantly larger than for Group $(M=2.83, S D=0.24), p=.002$. For the main effect of learning style, the mean of level of proficiency for $4(M=3.72, S D=0.44)$ was significantly larger than for Individual $(M=2.77, S D=0.26), p=.002$. No other significant effects were found.

\subsection{CONCLUSIONS AND DISCUSSIONS}

\subsection{Keys findings of the study}

The results of the study revealed that there was a statistically significant difference in the uses of reading strategies by different learning styles. The Visual language learners used the most reading strategies $(M=2.92)$. The Auditory language learners ranked 


\section{The Relationship between Prefered Learning Styles, Reading Strategies and Reading Achievement of Efl at Thai Nguyen University, Vietnam}

the second $(M=2.50)$. Tactile and Kinesthetic learners used reading strategies at low level $(M=2.0)$. Group language learners used the least reading strategies $(\mathrm{M}=1.04)$.

In terms of reading achievement among different learning styles, the results of the study showed that there was a statistically difference on the reading achievement for different learning styles. The Visual language learners achieved highest scores $(M=5.49)$. Tactile language learners ranked the second of $M=4.5$. Auditory and Kinesthetic language learners scored almost similar of $\mathrm{M}=3.36$ and $\mathrm{M}=3.72$ respectively. Group and Individual learners ranked the last of $\mathrm{M}=2.83$ and $\mathrm{M}=2.77$.

\subsection{Limitations of the study}

The study was carried out with a small size of sample so the findings from the study might not be generalizable to other language teaching and learning context. However, the study, in the first place would provide a brief description of the preferred learning styles of the students at Thai Nguyen University. In the second place, the study would be a guide for teachers in offering practical teaching styles and strategies to match their students' learning styles.

\subsection{Further suggestions}

The findings from the current study can be used as a basis for other researchers who wish to explore other aspects of learning styles such as the impacts of social and cultural setting to the formation of personal traits that lead to different preferred learning styles. Last but not least, the effects of learning styles can be a guide for teachers to adjust teaching styles to personalize the teaching and learning process.

\section{REFERENCES}

1) Anderson, N. J. (2003). Scrolling, clicking, and reading English: Online Reading strategies in a second/foreign language. The Reading Matrix, 3(3), 1-33.

2) Celce-Murcia, M. (2001). Teaching English as a second or foreign language. U.S.A: Heinle \& Heinle.

3) Claxton, C. S., \& Murrell, P. H. (1987). Learning styles: Implications for improving education practices. ASHE-ERIC Higher Education Report (Vol. 4). Washington, D.C.

4) Dunn, R. (1990). Understanding the Dunn and Dunn learning styles model and the need for individual. Journal of Reading, Writing, and Learning Disabilities International, 6, 223-247.

5) Farajolahi, S. \& Nimvari, A.A.E. 2014. The relationship between student learning styles and their language learning strategies. Modern Journal of Language Teaching Methods, 4(1):157-175

6) Felder, R.M. \& Spurlin, J. 2005. Applications, reliability and validity of the Index of Learning Styles. International Journal of Engaging Education, 21(1):103-112.

7) Gappi, L.L. 2013. Relationships between learning style preferences and academic performance of students. International Journal of Educational Research and Technology, 4(2):70-76.

8) Gay, L. R. (1996). Educational Research: Competencies for Analysis and Application. New Jersey: Merrill.

9) Kumar, R. (2011). Research Methodology: a step-by-step guide for beginners. SAGE Publications Ltd

10) Mulalic, A., Shad, P., \& Ahmad, F. (2009). Perceptual learning styles of ESL students. European Journal of Social Sciences, 7(3), 101-112. Retreieved from www.eurojournals.com/ejss7310.pdf

11) Prichard, A. (2009). Ways of learning - Learning theories and learning styles in the classroom. $2^{\text {nd }}$ Ed. Routledge

12) Reid, J. M. (1987). The learning style preferences of ESL students. TESOL Quarterly, 21(1), 87-111. Retreieved from JSTOR database.

13) Reid, J. M. (Ed.). (1995). Learning Styles in the ESL/ EFL Classroom. Boston: Heinle \& Heinle.

14) Sheorey, R., \& Mokhtari, K. (2001). Differences in the metacognitive awareness of reading strategies among native and non-native readers. System, 29, 431-449. doi: 10.1016/S0346-251X(01)00039-2

15) Tuan, L. T. (2011). EFL learners' learning styles and their attributes. Mediterranean Journal of Social Sciences, 2(2), 299- 320.

\section{ABOUT AUTHORS}

Dr. Dang Thi Thanh Huong is currently the vice Rector of the School of Foreign Language, Thai Nguyen University. She earned her Bachelor of English Language Teaching from Thai Nguyen University of Education. She obtained Master and Ph.D. degrees at Laguna University of The Philippines. Her interests include Language Teaching Methodology and Applied Linguistics.

Nguyen Thi Bich Diep is currently an office worker at Thai Nguyen University of Remoted Education. She is about to gain Master degree in Linguistics at the School of Foreign Languages. Her interest include Language teaching and Language Assessment. 